\title{
Quantitative Experimental and Theoretical Analysis of Photoinduced Relaxation Processes in Self-Assembled Porphyrin Triads
}

\author{
Eduard I. Zenkevich, ${ }^{\mathrm{a}}{ }^{@}$ Dmitri Kilin, ${ }^{\mathrm{b}}$ Christian von Borczyskowski, ${ }^{\mathrm{c}}$ \\ and Dietrich R. T. Zahn ${ }^{\mathrm{c}}$ \\ ${ }^{a}$ Belarussian National Technical University, 220013 Minsk, Belarus \\ ${ }^{\mathrm{b}}$ North Dakota State University, PO Box 6050, Fargo, North Dakota, USA \\ 'Institute of Physics, Chemnitz University of Technology, D-09107 Chemnitz, Germany \\ ${ }^{@}$ Corresponding author E-mail: zenkev@tut.by
}

\begin{abstract}
The main non-radiative competitive relaxation processes (excitation energy transfer and photoinduced electron transfer) were quantitatively studied for self-assembled triads based on Zn-octaethylporphyrin chemical dimer (the energy/electron donor) and dipyridyl substituted porphyrin extra-ligands (acceptors) in toluene using steadystate spectroscopy, time correlated single photon counting technique, and femtosecond pump-probe spectroscopy. It was found that the dimer fluorescence quenching and decay shortening (from ns to ps time scale) in triads reflect the manifestation of both indicated deactivation channels. The comparative role of the energy and electron transfer processes were experimentally tested upon temperature variation and solvent polarity changes (addition of acetone to toluene solutions) followed by calculations using Foerster and Marcus theories. In addition, for the porphyrin extraligand in the triads, a fluorescence decay time shortening (by 1.3-1.6 times in toluene at $293 \mathrm{~K}$ ) is observed which becomes stronger with increasing solvent polarity as well as temperature lowering (from $278 \mathrm{~K}$ down to $160 \mathrm{~K}$ ). The possible reasons and mechanisms of the non-radiative deactivation of locally excited $S_{1}$ states in the triads are discussed taking into account a close lying charge-separated state. The experimental data obtained are analyzed using the reduced density matrix formalism.
\end{abstract}

Keywords: Porphyrins, porphyrin chemical dimers, self-assembled porphyrin triads, picosecond and femtosecond spectroscopy, energy and charge transfer, fluorescence lifetime shortening, donor-acceptor interactions, reduced density matrix formalism.

\section{Количественный экспериментальный и теоретический анализ релаксационных процессов в самособирающихся триаАах порфиринов}

\author{
Э. И. Зенькевич, ${ }^{a}$ А. Килин, ${ }^{\mathrm{b}}$ K. фонон Борцисковски, ${ }^{\mathrm{c}}$ А. Р. Т. Цан \\ ${ }^{\mathrm{a}}$ Белорусский наџиональный технический университет, 220013 Минск, Беларусь \\ ' Государственный университет Северной Дакоть, n/я 6050, Фарго, Северная Дакота, США \\ 'Институт физики, Технический университет Хемнития, D-09107 Хемнити, Германия \\ ${ }^{@}$ E-mail: zenkev@tut.by
}

\begin{abstract}
Основные конкурирующие безызлучательные релаксационные процессы (перенос энергии возбуждения и фотоиндуциированный перенос электрона) количественно исследованы в самособирающихся триадах на основехимического димера Zn-октаэтилпорфирина (донора энергии/электрона) и дипиридилзамещенного порфиринового экстра-лиганда (акцептора) в толуоле методами коррелированного счета фотонов и фемтосекундной транзиентной спектроскопии. Обнаружено, что тушение и сокращение длительности (с нс до nс) флуоресценции димера в триадах связано с проявлением двух указанных выше каналов дезактивации. Конкурирующая роль процессов переноса энергии и электрона была экспериментально исследована при вариации температуры и полярности растворителя (добавление ацетона в толуольные
\end{abstract}


растворы), а также расчетами в рамках теорий Ферстера и Маркуса. Кроме того, для порфиринового экстра-лиганда в составе триад наблюдается сокращение длительности флуоресценции (в 1.3-1.6 раз в толуоле при 293 K), которое усиливается при возрастании полярности, а также при понижении температуры (с $278 \mathrm{~K}$ до $160 \mathrm{~K}$ ). Обсуждаются возможные причины и механизмы безызлучательной дезактивации локально возбужденных $S_{1}$-состояний в триадах с учетом близко расположенного состояния с переносом заряда. Полученные экспериментальные результаты анализируются в рамках метода редуцчированной матриц̧ь плотности.

Ключевые слова: Порфирины, химические димеры порфиринов, самособирающиеся триады порфиринов, пикосекундная и фемтосекундная спектроскопия, перенос энергии и заряда, тушение возбужденных состояний, метод редуцированной матрицы плотности.

\section{Introduction}

The process of photosynthesis in the biosphere is a culmination of evolutionary attempts by living organisms to harvest solar energy over the last 3.5 billion years and is the most important process that supplies the energy required for the survival of all living bioobjects. ${ }^{[1,2]}$ Primary photosynthetic events start with the absorption of light by chlorophyll molecules in a light-harvesting antenna. A light-harvesting antenna consists of many self-assembled chromophores collecting light energy and delivering it to a reaction center where transmembrane charge separation takes place, leading to the storage of chemical energy. In fact, hundreds of light-absorbing molecules in lightharvesting antennas are associated with a single reaction center in higher plant species. ${ }^{[3-5]}$

Correspondingly, it is not surprising that sophisticated energy-conversion nanostructures found in natural objects have inspired chemists to produce artificial counterparts as models for mimicking and to study the electronic excitation energy transfer processes and photoinduced charge separation taking place within in vivo systems. ${ }^{[2}$ and refs herein, 6-15] Typically, chlorophylls and bacteriochlorophylls, as well as porphyrins of various classes are the mostly used chromophores in various artificial settings. To understand the structure-function correlations for the light-harvesting processes and to create biomimetic energy transduction devices with possible applications in modern nanotechnologies, ${ }^{[16-18]}$ various attempts have been made to construct and study artificial multicomponent nanoassemblies using two basic bottom-up approaches known as covalent and noncovalent ones. ${ }^{[8,9,19,20]}$ The covalent approach is considered to be one way of supramolecular chemistry which provides a vast range of diverse supramolecular systems with a pronounced light harvesting and/or charge separation properties. On the other hand, to prepare large multicomponent artificial complexes the noncovalent, supramolecular approach may be more suitable rather than synthesizing the whole covalently constructed macromolecule. In the latter case, the information for self-assembly should be built into the structure of the building-block multimolecular components.

To date, this direction is the so-called supramolecular organic chemistry/photochemistry, a highly interdisciplinary field of science covering chemical, physical, and biological features of chemical species held together and organized by means of intermolecular binding interactions of various types. For the majority of conformationally restricted, structurally and energetically well-defined multiporphyrin moieties, the elucidation of the mechanisms and dynamics of energy transfer processes as well as the intrinsic peculiarities of charge separation and charge recombination of the product ion pair state are still the most fundamental and important problems. Noteworthy, despite intensive and wide research in this field, some concrete (numerical) aspects of the light collection and distant electron transfer reactions remain not understood yet.

In general, the interest in self-assembled organic and inorganic nanostructures has steadily grown in the past two decades..$^{[9,16-18]}$ Such interest was initially motivated by an academic desire to understand their optical and photophysical properties, but has more recently been strengthened by several technological developments based on exploiting some of these properties. Applications in optical and electronic devices (optical limiters, photovoltaic cells, light-accumulating units, etc.) have been supplemented by the high potential for use in nanobiomedicine. ${ }^{[17]}$ These applications have created a stronger need to describe the mechanisms of primary photoprocesses in such nanostructures in order to prepare new materials with predicted and driven functionalities.

The intention of this paper is not a thorough theoretical description of all the relaxation processes in multiporphyrin moieties, which would be too early given the open problems as well as some specific structural aspects. The present work should rather be viewed as a more quantitative characterization of the main competitive photoinduced relaxation processes (namely, Foerster resonance energy transfer, FRET, ${ }^{[1-23]}$ and photoinduced electron transfer, $\mathrm{PET}^{[24-26]}$ ) for self-assembled porphyrin triads in solutions upon variation of the temperature and solvent polarity. Our approach is based on the main three aspects: i) preparation of relatively rigid porphyrin triads of well-defined geometry containing electronically interacting macrocycles having given spectral, energetic and redox properties; ii) quantitative experimental verification of pathways and rate constants of excited states relaxation (based on steady-state and picosecond/femtosecond time-resolved spectroscopy); iii) theoretical analysis using the reduced density matrix formalism taking into account FRET, PET, and the dephasing of coherence between the excited electronic states of the triad. 


\section{Experimental}

\section{Materials}

Self-assembled triads of various but controllable geometry (Figure 1) were formed (using the extra-ligation effects via coordinative $\mathrm{Zn}-\mathrm{N}$ interactions) $)^{[9,27,28]}$ from a covalently linked Zn-octaethylporphyrin dimer, (ZnOEP), Ph, as the energy/ electron donor $D$, and dipyridyl-substituted porphyrin free base $\mathbf{H}_{2} \mathbf{P}$, as the corresponding energy/electron acceptors $A$. The synthesis, identification, and purification of the dimer (ZnOEP), Ph, 1,4-bis\{zinc(II)-5-(2,3,7,8,12,13,17,18-octaethylporphyrinyl)\} benzene and corresponding monomeric extra-ligands were performed by Dr. A. Shulga and described earlier. ${ }^{[29]}$ It was shown ${ }^{[9,27,28]}$ that the matching geometry between $\mathrm{N}$ atoms in pyridyl containing extra-ligands and the $\mathrm{Zn}-\mathrm{Zn}$ distance in the dimers and trimers plays the essential role in the formation of triads and pentads with relatively well defined conformational rigidity. Due to the two-point coordination interaction all self-assembled triads are characterized by complexation constants $K_{\mathrm{C}} \sim 10^{6} \mathrm{M}^{-1} \div 10^{7} \mathrm{M}^{-1}$ that is by approximately two orders of magnitude higher with respect to those found for dipyridinated complexes of the dimer (ZnOEP), Ph. Concluding, namely the conformationally rigid morphology of the triads under study characterized by experimentally and theoretically proven orientation and distances between interacting subunits presents itself the necessary background for the reasoned comparison of the obtained experimental values with the corresponding theoretical calculations of energy/electron transfer parameters.

\section{Solvents}

Toluene, acetone, methylcyclohexane (Aldrich HPLC grade) were used without further purification. Steady-state and timeresolved fluorescence measurements were carried out in quartz optical cuvettes (Hellma QS 27 111, path length $1 \mathrm{~cm}$ ). The optical density of the solutions was OD $\leq 0.15$ in order to avoid reabsorption effects. In pump-probe experiments $\mathrm{OD} \approx 0.3-0.5$ was used.

\section{Spectral and Time-Resolved Measurements}

Steady-state fluorescence and excitation spectra were recorded on a Shimadzu RF-5001PC spectrofluorimeter and absorption spectra - on a Shimadzu UV-3101PC spectrophotometer.

In order to analyze multicomponent fluorescence kinetics, time correlated single photon counting (TCSPC) experiments were performed using a picosecond laboratory home-made setup with the system response $\Delta t_{1 / 2}=75$ ps. The convolution of multicomponent fluorescence kinetics (based on decay associated spectra) was performed three times for each data-set using global analysis in a commercial software programs (Globals for Spectroscopy, FluoFit) with the minimization of chisquare values $\chi^{2}$. All experimental details were described earlier. ${ }^{[30]}$

Pump-probe measurements were carried out using a femtosecond laboratory home-made setup with an experimental response $\Delta \mathrm{t}_{1 / 2} \sim 280 \mathrm{fs}$. The kinetics were deconvoluted using a multiexponential fit. The details of the experimental setup were presented in our earlier papers. ${ }^{[30,31]}$ Time-resolved TCSPC and pump-probe experiments were performed in a homemade quartz cell equipped with a mini-motor for solution circulation (volume of $9 \mathrm{~mL}$ ) in order to avoid artefacts caused by a possible photodecomposition of the compounds.

For temperature dependent measurements a homemade cryostat was used equipped with a ITC502 (Oxford Instruments) temperature controller.

\section{Results and Discussion}

\section{Spectral-Kinetic Properties Based on Steady-State and Time-Resolved Measurements}

It was shown by us earlier ${ }^{[27,30]}$ that upon titration in non-polar solvents at $293 \mathrm{~K}$, the porphyrin chemical dimer (ZnOEP) $\mathbf{2} \mathbf{P h}$ and porphyrin extra-ligands $\mathbf{H}_{2} \mathbf{P}$ form self-assembled 1:1 triads. Spectral transformations reflecting the triad formation are shown in Figure 2. Upon triad formation a red shift of the dimer long wavelength absorption $Q_{\mathrm{x}}(0,0)$ band is observed accompanied by a dimer fluorescence quenching and a relative rise of the extraligand emission. In fact, absorption spectra of the triads are essentially a linear combination of the corresponding dipyridinated dimer and extra-ligand. This means that the interaction between two subunits is weak and they retain their individual identities.

It is seen also from Figure $2 \mathrm{~B}$ that the fluorescence spectra of the triad are characterized by a strong quenching of the dimer fluorescence, and the fluorescence spectra of the triad mainly consist of the extra-ligand fluorescence bands. In addition, Figure 3B (curve 1) shows
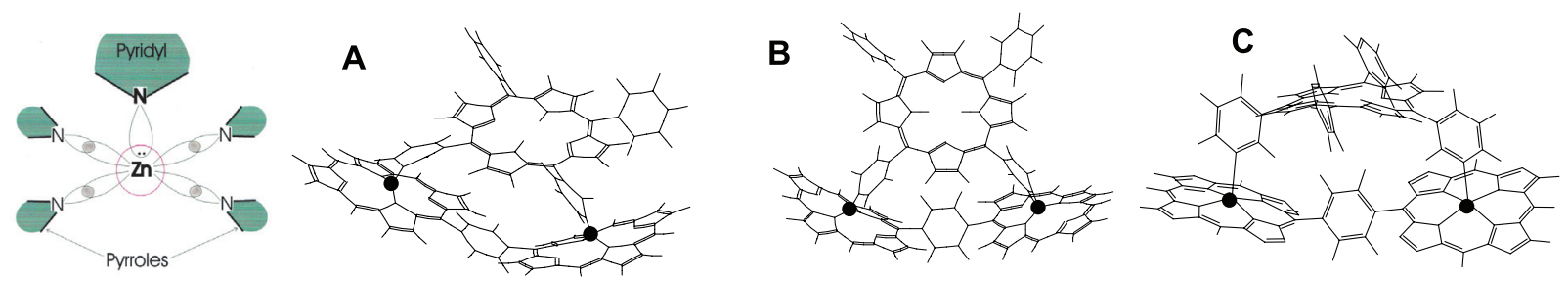

Figure 1. Schematic presentation of "key-hole" principle of the non-covalent coordination Zn....N-pyr with a perpendicular disposal of the extra-ligand with respect to the porphyrin macrocycle plane as well as mutual arrangement of interacting subunits and estimated geometrical parameters for optimized triads containing chemical dimer $(\mathbf{Z n O E P})_{2} \mathbf{P h}$ and porphyrin free base $\mathbf{H}_{2} \mathbf{P}$, containing two mesophenyl and two meso-pyridyl rings with different positions of both pyridyl rings (opposite and adjacent) and pyridyl nitrogens $\mathbf{N}$ (meta and para), based on quantum-chemical calculations. Central $\mathrm{Zn}$ ions in the dimer are shown by black balls. A: extra-ligation via adjacent meta-pyridyl rings $\left(\boldsymbol{m}^{\wedge} \mathbf{P y r}\right)_{2}$ with $l_{\mathrm{N}-\mathrm{N}}=10.0 \AA, d_{\mathrm{Zn}-\mathrm{Zn}}=12.23 \AA, r_{\mathrm{DA}}=8.8 \AA, R_{\text {Plane-Plane }}=6.7 \AA$; $\mathbf{B}$ : extra-ligation via adjacent para-pyridyl rings $\left(\boldsymbol{p}^{\wedge} \mathbf{P y r}\right)_{2}$, with $l_{\mathrm{N}-\mathrm{N}}=12.2 \AA, d_{\mathrm{Zn}-\mathrm{Zn}}=12.45 \AA, r_{\mathrm{DA}}=13.7 \AA, R_{\text {Plane-Plane }}=12.2 \AA$; C: extra-ligation via opposite meta-pyridyl rings $(\boldsymbol{m} \text {-Pyr })_{2}$ with $l_{\mathrm{N}-\mathrm{N}}=15.1 \AA, d_{\mathrm{Zn}-\mathrm{Zn}}=12.86 \AA, r_{\mathrm{DA}}=8.2 \AA, R_{\text {Plane-Plane }}=5.0 \AA$. $r_{\mathrm{DA}}$ denotes the intercenter distance, $l_{\mathrm{N}-\mathrm{N}}$ corresponds to the distance between two extra-ligand nitrogens interacting with two central $\mathrm{Zn}$ ions of the dimer, $d_{\mathrm{Zn}-\mathrm{Zn}}$ is the distance between two central $\mathrm{Zn}$ ions of the dimer in the triad, $R_{\text {Plane-Plane }}$ and $R_{\text {Center-Center }}$ are interplane and intercenter distances correspondingly between dimer and porphyrin extra-ligand. 

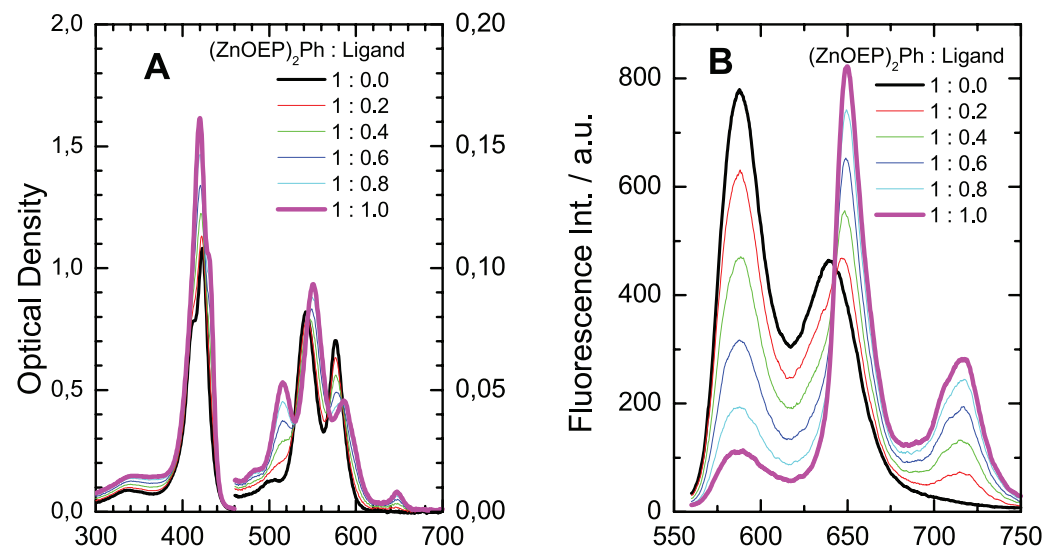

Figure 2. Absorption (A) and fluorescence $\left(\mathbf{B}, \lambda_{\mathrm{ex}}=546 \mathrm{~nm}\right.$, isosbestic point) spectra of the dimer (ZnOEP) $\mathbf{P h}$ with increasing amounts of extra-ligand $\mathbf{H}_{2} \mathbf{P}\left(\boldsymbol{m}^{\wedge} \mathbf{P y r}\right)_{2}$ leading to the formation of the triad $(\mathbf{Z n O E P})_{2} \mathbf{P h} \otimes \mathbf{H}_{2} \mathbf{P}\left(\boldsymbol{m}^{\wedge} \mathbf{P y r}\right)_{2}-(\mathbf{P h})_{2}$. Symbol $\otimes$ denotes that components are coupled in the triad. The concentration of $(\mathbf{Z n O E P})_{2} \mathbf{P h}$ at the beginning of titration is $C_{\mathrm{D} 0}=1.9 \cdot 10^{-6} \mathrm{M}$ in toluene at $293 \mathrm{~K}$; the dimer:ligand molar ratio varies from $\mathrm{x}=1: 0$ to $1: 1(0.0,0.2,0.4,0.6,0.8,1.0)$. Bold pink curves correspond to the triad spectra (structure $\mathbf{A}$ in Figure 1). The low-intense unshifted fluorescence band at $\lambda_{\max }=586 \mathrm{~nm}$ in triad solution at $\mathrm{x}=1: 1$ belongs to the remaining uncomplexed dimer.

that the fluorescence excitation spectrum of the triad $(\mathrm{ZnOEP})_{2} \mathbf{P h} \otimes \mathbf{H}_{2} \mathbf{P}\left(m^{\wedge} \mathbf{P y r}\right)_{2}$ in pure toluene (monitored at $720 \mathrm{~nm}$ where the majority of the emission comes from the extra-ligand) contains bands at $549 \mathrm{~nm}$ and $587 \mathrm{~nm}$ belonging to the absorption of the dimer. Correspondingly, as far as there is a good spectral overlap between the dimer fluorescence spectrum and extra-ligand absorption bands it seems to be reasonable to connect the (ZnOEP) $\mathbf{P h}$ emission quenching with the excitation energy transfer (EET) processes in the triads. Quite obviously EET dimer $\rightarrow$ extraligand has to lead to the sensitized emission of the latter. On the basis of the comparison of absorption and fluorescence excitation spectra for triads under consideration (structures A, B, C in Figure 1) the experimental efficiency of singletsinglet EET was estimated to be $\Phi_{\mathrm{EET}}=70-80 \%$ in pure toluene at ambient temperature.

For porphyrin chemical dimers with various structures and properties of coupled macrocycles we demonstrated that at intercenter distances $r_{\mathrm{DA}}=10.6-12.3 \AA$ the Foerster theory of inductive resonance ${ }^{[21-23]}$ is still applicable to weakly interacting porphyrin chromophores (as far as the effective length of interacting dipoles $\left.|\mu|<r_{\mathrm{DA}}\right)$, and theoretical calculations of EET parameters are in a reasonable agreement with experimental estimations. ${ }^{[32,33]}$ Correspondingly,

Table 1. Energy transfer parameters for triads based on the dimer (ZnOEP) $\mathbf{P} \mathbf{P h}$ and $\mathbf{H}_{2} \mathbf{P}$ ligands (toluene, $293 \mathrm{~K}$, refractive index $n=1.4968$ ).

\begin{tabular}{|c|c|c|c|c|c|c|c|c|c|c|}
\hline No & $\begin{array}{c}\text { System / } \\
\text { Triad }\end{array}$ & Donor-acceptor pair & $\tau_{\mathrm{D}}^{0}, \mathrm{~ns}$ & $\varphi_{\mathrm{D}}^{0}$ & $\begin{array}{l}\varepsilon_{\mathrm{A}},\left(\lambda_{\max }\right) \\
\mathrm{M}^{-1} \cdot \mathrm{cm}^{-1}\end{array}$ & $\begin{array}{c}r_{\mathrm{DA}}, \\
\AA\end{array}$ & $\begin{array}{c}J, 10^{-14} \\
\mathrm{~cm}^{3} \cdot \mathrm{M}^{-1}\end{array}$ & $k^{2}$ & $\begin{array}{l}R_{0}^{\text {theor }}, \\
\AA\end{array}$ & $\begin{array}{c}k_{\mathrm{EET}}, \\
10^{10} \mathrm{~s}^{-1}\end{array}$ \\
\hline & Dimer* & ZnOEP-Ph-ZnOEP & 1.15 & 0.012 & $24900(588)$ & 12.5 & 3.95 & 1.002 & 21.1 & 2.1 \\
\hline 1 & Triad A & $(\mathrm{ZnOEP})_{2} \mathbf{P h} \otimes \mathrm{H}_{2} \mathrm{P}\left(m^{\wedge} \mathrm{Pyr}\right)_{2}-(\mathrm{Ph})_{2}$ & 1.15 & 0.012 & $9100(654)$ & 8.8 & 4.18 & 0.760 & 20.3 & 13.7 \\
\hline 2 & Triad B & $(\mathrm{ZnOEP})_{2} \mathbf{P h} \otimes \mathrm{H}_{2} \mathbf{P}\left(p^{\wedge} \mathrm{Pyr}\right)_{2}-(\mathrm{Ph})_{2}$ & 1.15 & 0.012 & $9000(654)$ & 13.7 & 4.15 & 0.315 & 21.6 & 1.2 \\
\hline 3 & Triad C & $(\mathrm{ZnOEP})_{2} \mathrm{Ph} \otimes \mathrm{H}_{2} \mathrm{P}(m-\mathrm{Pyr})_{2}-(\mathrm{Ph})_{2}$ & 1.15 & 0.012 & $9000(655)$ & 8.2 & 4.19 & 0.525 & 21.7 & 14.6 \\
\hline
\end{tabular}

Comments: $\varphi_{\mathrm{D}}^{0}$ and $\tau_{\mathrm{D}}^{0}$ are experimentally measured fluorescence quantum yield and lifetime values for individual donor in the presence of $\mathrm{O}_{2}$ in solutions. *In the dimer both ZnOEP macrocycles are extra-ligated. Decimal extinction coefficients $\varepsilon_{\mathrm{A}}$ were measured with an average total error of $15 \%$, corresponding $\lambda_{\max }$ in $\mathrm{nm}$ as indicated in brackets. Intercenter donor-acceptor distances $r_{\mathrm{DA}}$ were estimated from optimised structures of the triads (see Figure 1). Energy transfer (EET) parameters were calculated using Foerster inductive-resonant model: ${ }^{[21]}$

Critical transfer distance $\left(R_{0}^{\text {theor }}\right)^{6}=\frac{9000 \cdot \ln 10 \cdot k^{2} \cdot \phi_{D}^{0}}{128 \pi^{5} n^{4} N_{A}} \times \int_{0}^{\infty} f_{D}(v) \varepsilon_{A}(v) \frac{d v}{v^{4}} \quad(1), N_{\mathrm{A}}$ is Avogadro number.

Spectral overlap integral $J=\int_{0}^{\infty} f_{D}(v) \varepsilon_{A}(v) \frac{d v}{v^{4}} \quad$ (2) was calculated on the basis of experimental acceptor absorption and donor fluorescence
spectra.

Orientational factors $k^{2}=\left[\operatorname{Cos}\left(\mu_{\mathrm{D}}, \mu_{\mathrm{A}}\right)-3 \operatorname{Cos}\left(\mu_{\mathrm{D}}, r_{\mathrm{DA}}\right) \times \operatorname{Cos}\left(\mu_{\mathrm{A}}, r_{\mathrm{DA}}\right)\right]^{2} \quad(3)$, where $\left(\mu_{\mathrm{D}}, \mu_{\mathrm{A}}\right)$ is the angle between transition dipole moment vectors of the $\mathrm{D}$ and $\mathrm{A}$ subunits, $\left(\mu_{\mathrm{D}}, r_{\mathrm{DA}}\right)$ and $\left(\mu_{\mathrm{A}}, r_{\mathrm{DA}}\right)$ denote the angles between the dipole vectors of $\mathrm{D}$ and $\mathrm{A}$, and the direction $\mathrm{D} \rightarrow \mathrm{A}$, respectively. $k^{2}$ values were calculated on the basis of optimized structures of the triads (see Figure 1) and oscillator models for ZnP-dimers and extra-ligands. Theoretical rate constants for EET process were calculated using Foerster expression $k_{\mathrm{EET}}=\left(1 / \tau_{\mathrm{S}}^{0}\right)\left(R_{0}^{\text {theor }} / r_{\mathrm{DA}}\right)^{6}$ 
we suppose that in porphyrin triads $\left(r_{\mathrm{DA}}=8.2-13.7 \AA\right.$, see Figure 1) we may apply the inductive-resonant model for the quantitative description of the non-radiative electronvibrational EET process. As a result, on the basis of optimized geometry of the triads (see Figure 1) and Foerster inductive-resonant model ${ }^{[21]}$ the main transfer parameters were calculated and summarized in Table 1.

Secondly, when applying the Foerster model to the triads under consideration one assumes that, besides the ETT process, there are no pathways for depopulating the $S_{1}$ state of the dimer other than the radiative decay and the intersystem crossing (internal conversion is neglected). From the data presented in Table 1 (last column) it follows that in all triads the lifetime of the dimer excited $S_{1}$ state has to be shorten to the picosecond time scale due to only one deactivation process, namely EET dimer $\rightarrow$ porphyrin extraligand.

However, some additional experimental findings for the triads led to the conclusion that the real non-radiative dynamics is not governed by S-S EET processes only. First, it was found that in non-polar toluene at $293 \mathrm{~K}$ upon direct excitation at $650 \mathrm{~nm}$ (absorption band of $\mathbf{H}_{2} \mathbf{P}$ ), the extra-ligand fluorescence quantum efficiency is reduced in the triad $(\mathbf{Z n O E P})_{2} \mathbf{P h} \otimes \mathbf{H}_{2} \mathbf{P}\left(\boldsymbol{m}^{\wedge} \mathbf{P y r}\right)_{2}-(\text { iso-PrPh })_{2}$ compared to that for individual $\mathbf{H}_{2} \mathbf{P}$ under the same conditions. Secondly, upon increasing solvent polarity via a subsequent vol.\% of acetone $(\varepsilon=20.7)$ addition to toluene some specific spectral effects are detected (Figure 3): i) the $\mathbf{H}_{2} \mathbf{P}$ fluorescence in the triads shows a noticeable decrease the while the individual extra-ligand does not show fluorescence quenching upon acetone addition (Figure 3A); ii) the excitation spectrum of the triad changes dramatically and becomes almost identical to that of the individual extra-ligand $\mathbf{H}_{2} \mathbf{P}\left(\boldsymbol{m}^{\wedge} \mathbf{P y r}\right)_{2}$-(iso-PrPh) $)_{2}$ (Figure 3B). Correspondingly, it follows from the results of Figure $3 \mathrm{~B}$ that the sensitisation effect due to S-S EET dimer $\rightarrow$ extra-ligand is absent in the last case, although the usual through-space singlet-singlet energy transfer in multiporphyrins arrays is hardly dependent on solvent polarity. ${ }^{[8,9,30]}$ At the same time, the data presented in Figure 3A evidently show that the dimer emission in the triad remains strongly quenched upon increasing solvent polarity.

In order to clarify the interplay between excited states of interacting subunits in triads, time-resolved picosecond TCSPC and femtosecond pump-probe experiments were carried out in toluene at ambient temperature (Figure 4). TCSPC measurements were performed exciting the dimer moiety at $545 \mathrm{~nm}$ and detecting the emission in the range of $570 \div 740 \mathrm{~nm}$ followed by a global fit analysis giving the decay associated spectra (Figure 4A). Two basic components were easily assigned both due to their decays as well as to the structure of the amplitude spectra to the rest of uncomplexed fluorescing dimers ( $\mathbf{Z n O E P})_{2} \mathbf{P h}$ and the complexed $\mathbf{H}_{2} \mathbf{P}$ extra-ligand (showing characteristic bands at 650 and $720 \mathrm{~nm}$ ). Thus, the main conclusion is that the fluorescence decays of extra-ligands in triads are reduced noticeably with respect to those for the corresponding individual uncomplexed porphyrin molecules in pure toluene. The decay time shortening increases upon increasing solvent polarity $\left(\tau_{\mathrm{S}}=5.5 \mathrm{~ns}\right.$ for $\mathbf{H}_{2} \mathbf{P}\left(\boldsymbol{m}^{\wedge} \mathbf{P y r}\right)_{2}-(\text { iso }-\mathbf{P r P h})_{2}$ in the triad in toluene +7 vol. $\%$ of acetone). The latter tendency correlates with a pronounced decrease of the extraligand fluorescence quantum yield (Figure 3A). It should be noted also that the fluorescence intensity of the $\mathbf{H}_{2} \mathbf{P}$ extra-ligand in the triad $(\mathbf{Z n O E P})_{2} \mathbf{P h} \otimes \mathbf{H}_{2} \mathbf{P}\left(m^{\wedge} \mathbf{P y r}\right)_{2}$-(iso$\mathbf{P r P h})_{2}$ is decreased upon lowering the temperature (from $278 \mathrm{~K}$ down to $160 \mathrm{~K}$ ). For the given triad, the activation energy was fitted by a Boltzman distribution function (const $+1 /[1+\exp (\Delta E / k \mathrm{~T})])$ giving the value $\Delta E=0.05 \mathrm{eV}$ in toluene $+7 \mathrm{vol} \%$ of acetone, while no activation energy was found in pure toluene. These experimental findings cannot be explained by S-S EET processes. In the given case, the photoinduced charge separation or other radiationless processes have to be taken into account.

Femtosecond pump-probe data presented for the triad $(\mathbf{Z n O E P})_{2} \mathbf{P h} \otimes \mathrm{H}_{2} \mathbf{P}\left(\boldsymbol{m}^{\wedge} \mathbf{P y r}\right)_{2}-(\text { iso-PrPh })_{2}$ in Figure 4B show the bleaching of the extra-ligand $Q$-bands at 515, 550, and $580 \mathrm{~nm}$ and the absorption band at $670-680 \mathrm{~nm}$ usually ascribed to the $\mathrm{Zn}$-porphyrin cation and other absorbing species. ${ }^{[25,31]}$ So, the formation of charge transfer (CT) states
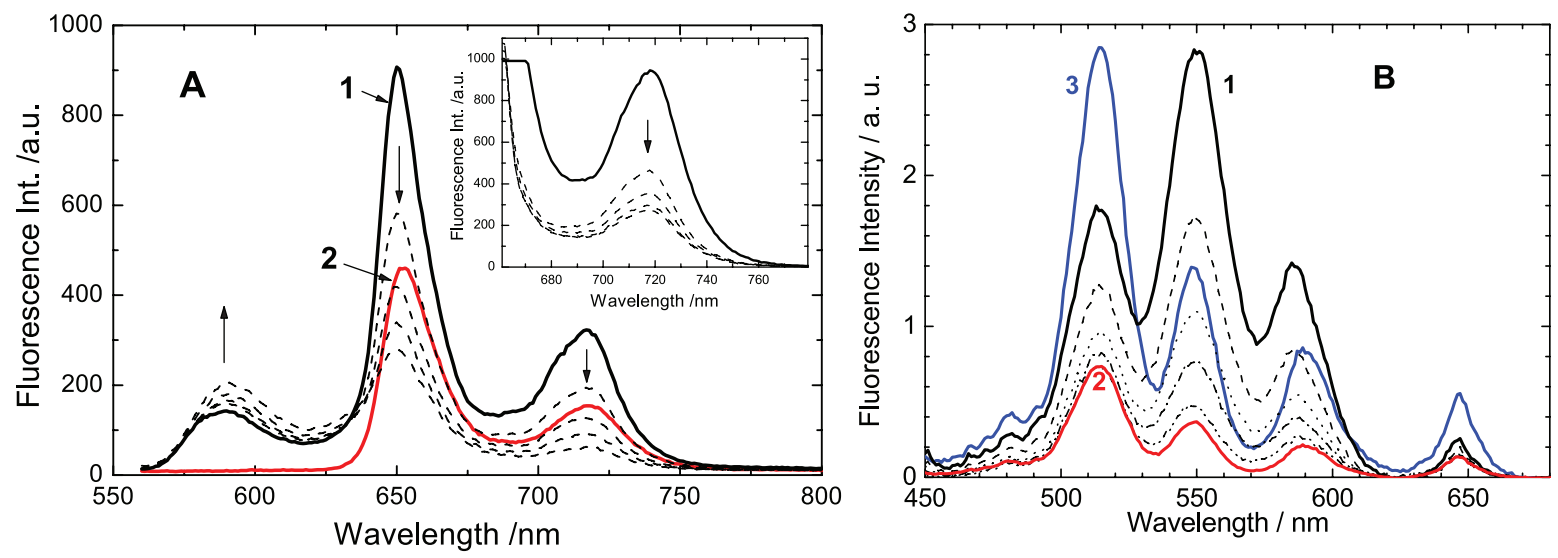

Figure 3. Fluorescence spectra $\left(\mathbf{A}, \lambda_{\mathrm{ex}}=546 \mathrm{~nm}\right)$ and fluorescence excitation spectra $\left(\mathbf{B}, \lambda_{\mathrm{det}}=720 \mathrm{~nm}\right)$ of the triad $(\mathbf{Z n O E P})_{2} \mathbf{P h} \otimes \mathbf{H}_{2} \mathbf{P}\left(\boldsymbol{m}^{\wedge} \mathbf{P y r}\right)_{2}-(\mathbf{P h})_{2}$ in toluene at $293 \mathrm{~K}$ plus 0 (curves 1), 3, 6, 9, 17 vol.\% of acetone (thin dashed lines, intensity decreases with increasing amount of toluene). Fluorescence of $\mathbf{H}_{2} \mathbf{P}$ in toluene at the same concentration as in triad (curve $\left.2 \mathrm{~A}\right)$. Insert: $\mathbf{H}_{2} \mathbf{P}$ fluorescence quenching in the triad upon increasing vol. $\%$ of acetone (direct excitation at $\lambda_{\mathrm{ex}}=650 \mathrm{~nm}$ ). Curve $3 \mathrm{~B}$ presents the excitation spectrum of $\mathbf{H}_{2} \mathbf{P}$ alone in toluene at the same concentration as in the triad. 

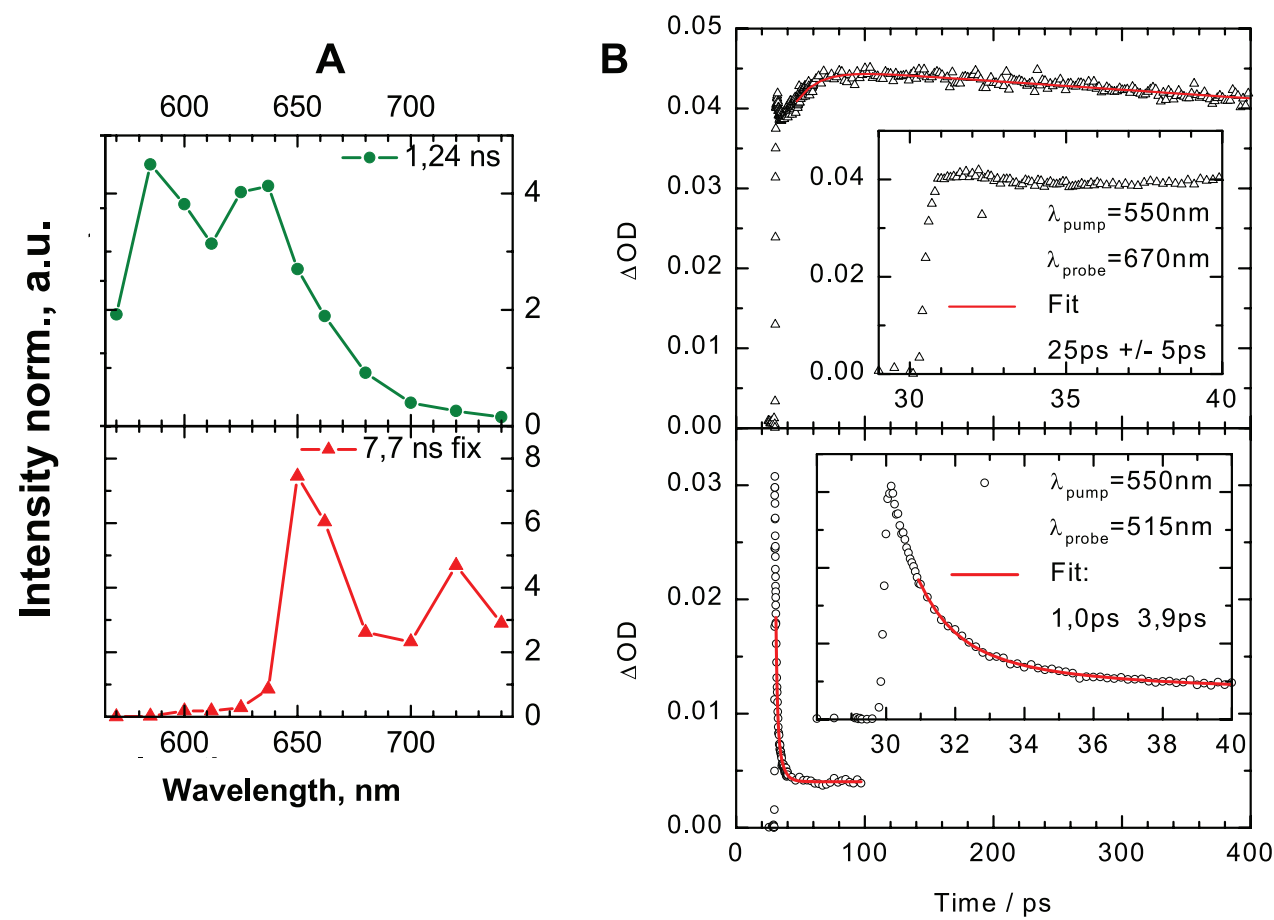

Figure 4. Time-resolved picosecond TCSPC (A) and femtosecond pump-probe $(\mathbf{B})$ experiments for the $\operatorname{triad}(\mathbf{Z n O E P})_{2} \mathbf{P h} \otimes_{2} \mathbf{P}\left(m^{\wedge} \mathbf{P y r}\right)_{2}{ }^{-}$ (iso-PrPh) ${ }_{2}$ (structure A, Figure 1) in toluene at $293 \mathrm{~K}$. A: Decay-associated spectra at $\lambda_{\mathrm{ex}}=546 \mathrm{~nm}$ obtained from global analysis fit of 12 measurements with $\chi^{2}=1.15$. B: Time evolution of transient absorbance at $\lambda_{\text {pump }}=555 \mathrm{~nm}$ (excitation) and probed at $515 \mathrm{~nm}$ (top) and 680 nm (bottom).

could be appropriately detected. We found that upon pumping at $555 \mathrm{~nm}$ (in the dimer absorption band) the increase of $\mathbf{H}_{2} \mathbf{P}$ ground state bleaching at $510 \mathrm{~nm}$ (formed by $\mathbf{H}_{2} \mathbf{P}^{*}$ or $\left.\mathbf{H}_{2} \mathbf{P}^{-}\right)^{[25,31]}$ is observed after an immediate rise at time zero. The decay was fitted with a time constant of $1.6 \pm 0.1 \mathrm{ps}$. The dynamics of the absorption at $670-680 \mathrm{~nm}$ are quite complex exhibiting an immediate rise which is followed by a decay with $1.7 \mathrm{ps}$ and a slower rise of $60 \mathrm{ps}$. These results show that the non-radiative complex relaxation of the dimer $\mathrm{S}_{1}$ state in the triads takes place within $\sim 1.7 \mathrm{ps}$.
It follows from the results of "polarity-temperature" experiments presented in Figure 3 as well as from timeresolved measurements presented in Figure 4, that the additional deactivation of the extra-ligand locally excited $\mathrm{S}_{1}$ state in this case may be connected with charge transfer processes while the non-radiative deactivation of the dimer locally excited $\mathrm{S}_{1}$ state is caused by both EET and the photoinduced electron transfer, PET, processes. The results obtained show that the competition between ETT and PET non-radiative channels may be driven by properties of the environment.

Table 2. Structural and electron transfer parameters for self-assembled triads based on the dimer (ZnOEP) $\mathbf{P}_{2} \mathbf{P h}$ and $\mathbf{H}_{2} \mathbf{P}$ extra-ligands (toluene, $293 \mathrm{~K}$ ).

\begin{tabular}{|c|c|c|c|c|c|c|c|c|c|}
\hline No & Donor-acceptor pair & $r_{\mathrm{DA}}, \AA$ & $E_{\mathrm{A}}^{\mathrm{red}}, \mathrm{eV}$ & $E\left(\mathrm{~S}_{1}^{\mathrm{L}}\right), \mathrm{eV}$ & $\Delta G_{\mathrm{S}}, \mathrm{eV}$ & $E(\mathrm{CT}), \mathrm{eV}$ & $\tau_{\mathrm{s} 0}^{\text {Dim }}, \mathrm{ns}$ & $\tau_{\mathrm{s} 0}{ }^{\mathrm{L}}, \mathrm{ns}$ & $\tau_{\mathrm{S}}^{\mathrm{L}}, \mathrm{ns}$ \\
\hline 1 & $(\mathrm{ZnOEP})_{2} \mathbf{P h} \otimes \mathrm{H}_{2} \mathbf{P}\left(m^{\wedge} \mathrm{Pyr}\right)_{2}-(\mathrm{Ph})_{2}$ & 8.8 & -0.98 & 1.91 & 0.287 & 1.90 & 1.15 & 9.5 & 7.7 \\
\hline 2 & $(\mathrm{ZnOEP})_{2} \mathbf{P h} \otimes \mathrm{H}_{2} \mathbf{P}\left(p^{\wedge} \mathrm{Pyr}\right)_{2}-(\mathrm{Ph})_{2}$ & 13.7 & -0.98 & 1.91 & 0.287 & 1.90 & 1.15 & 9.4 & 8.6 \\
\hline 3 & $\mathrm{ZnOEP})_{2} \mathbf{P h} \otimes \mathrm{H}_{2} \mathbf{P}(m-\mathrm{Pyr})_{2}-(\mathbf{P h})_{2}$ & 8.2 & -0.98 & 1.91 & 0.287 & 1.90 & 1.15 & 9.3 & 6.2 \\
\hline
\end{tabular}

Notes: Intercenter distances $r_{\mathrm{DA}}$ were estimated from optimised structures of the triads (Figure 1). The oxidation potential for coordinated dimer $(\mathrm{ZnOEP})_{2} \mathbf{P h}$ was taken to be $E_{\mathrm{D}}{ }^{\text {ox }}=0.63 \mathrm{~V}$ (like for pyridinated $\mathbf{Z n O E P}$ in dimethylformamide, DMF, $v s \mathrm{SCE}$ ), the reduction potential $E_{\mathrm{A}}{ }_{\mathrm{r}}^{\text {red }}$ for extra-ligand was extracted from literature data (in DMF vs SCE) taking into account that pyridyl substituents increase the reduction potential of free base porphyrins. The energy levels of the extra-ligand locally excited $\mathrm{S}_{1}$ states $E\left(\mathrm{~S}_{1}^{\mathrm{L}}\right)$ were determined on the basis of the corresponding fluorescence and absorption $Q(0,0)$ bands. The energy levels of the ion pair states in toluene were estimated by: ${ }^{[33]} E(\mathrm{CT})=e\left(E_{\mathrm{D}}{ }^{\text {ox }}-E_{\mathrm{A}}\right.$ red $)+\Delta G_{\mathrm{S}}$ (5). Term $\Delta G_{\mathrm{S}}$ corrects effects of solvent polarity as well as the Coulombic stabilization energy between the charged donor and acceptor and was calculated as ${ }^{[24,25,33]} \Delta G_{\mathrm{S}}=\frac{e^{2}}{4 \pi \varepsilon_{0}}\left[\left(\frac{1}{2 r_{\mathrm{D}}}+\frac{1}{2 r_{\mathrm{A}}}-\frac{1}{r_{\mathrm{DA}}}\right) \frac{1}{\varepsilon}-\left(\frac{1}{2 r_{\mathrm{D}}} \frac{1}{\varepsilon_{\mathrm{D}}}+\frac{1}{2 r_{\mathrm{A}}} \frac{1}{\varepsilon_{\mathrm{A}}}\right)\right]$,

where dielectric constants are $\varepsilon$ (toluene) $=2.38$ or $\varepsilon$ (methylcyclohexane) $=2.02$, and $\varepsilon_{\mathrm{A}}=\varepsilon_{\mathrm{D}}=36.7\left(\mathrm{DMF}^{[34]}\right)$, where redox potentials were measured). $\tau_{\mathrm{S} 0}{ }^{\mathrm{Dim}}$ is the measured fluorescence decay for an individual dimer in toluene+pyridine, $\tau_{\mathrm{S} 0}{ }^{\mathrm{L}}$ and $\tau_{\mathrm{S}}{ }^{\mathrm{L}}$ are the fluorescence lifetimes for the individual extra-ligand and in the triad, correspondingly. 
This competition leads to the complex dynamics of the deactivation of locally excited states in the triads. In order to analyze this situation in more detail the necessary parameters for PET events in the triads were obtained and presented in Table 2.

Quite obviously in triads, there is an EET process from the dimer (ZnOEP) $\mathbf{P h} \rightarrow$ extra-ligand, which leads to the stimulated fluorescence of the extra-ligand. The data presented in Table 2 evidently show that at ambient temperature in non-polar toluene the energy of the charge transfer state $E(\mathrm{CT})$ is relatively lower than the energy of the locally excited $\mathrm{S}_{1}$ state of the extra-ligand $\mathbf{H}_{2} \mathbf{P}$ for all triads: $E(\mathrm{CT})$ $<E\left(\mathrm{~S}_{1}{ }^{\mathrm{L}}\right)$. It means that in these conditions, upon excitation of the triad into the dimer absorption bands the population/ depopulation of the extra-ligand locally excited $\mathrm{S}_{1}$ state may be realized not only via the direct EET (ZnOEP) $)_{2} \mathbf{P h} \rightarrow$ extra-ligand but additionally via combined charge transfer processes with participation of an existing charge transfer (CT) state. From the data collected in Table 2 one may calculate the Gibbs free energy $\Delta G^{0}$ of the photoinduced electron transfer (PET) processes reaction according to ${ }^{[33]}$ $\Delta G^{0}=E(\mathrm{CT})-E\left(\mathrm{~S}_{1}{ }^{\mathrm{D}}\right)=e\left(E_{\mathrm{D}}{ }^{\text {ox }}-E_{\mathrm{A}}{ }^{\mathrm{red}}\right)+\Delta G_{\mathrm{S}}$

It was found that for all triads under study (structures A, B, C, Figure 1) $\Delta G^{0}<0$. It means that for these selfassembled complexes, according to Marcus theory, ${ }^{[24-26]}$ adiabatic PET is realized in a "normal" region.
Correspondingly, such competition between EET and the photoinduced charge transfer processes manifests itself in a fast complex spectral dynamics observed in transient absorption spectra of the triad (ZnOEP) $)_{2} \mathbf{P h} \otimes \mathbf{H}_{2} \mathbf{P}\left(\boldsymbol{m}^{\wedge} \mathbf{P y r}\right)_{2}$-(iso-PrPh $)_{2}$ (Figure 4B). To analyze this competition, we simulated the complex dynamics using the method of balance equations for the energy level scheme as depicted in Figure 5.

The analysis of the extra-ligand $\mathbf{H}_{2} \mathbf{P}$ bleaching at $515 \mathrm{~nm}$ in femtosecond pump-probe experiments for the triad $(\mathbf{Z n O E P})_{2} \mathbf{P h} \otimes_{2} \mathbf{P}\left(\boldsymbol{m}^{\wedge} \mathbf{P y r}\right)_{2}$-(iso-PrPh $)_{2}$ (Figure 4B) shows that the singlet excited $\mathbf{H}_{2} \mathbf{P}^{*}$ or $\mathrm{CT} \mathbf{H}_{2} \mathbf{P}^{-}$states are formed with a time constant of $1.6 \mathrm{ps}$. From the static spectra it is obvious that sensibilization via the dimer (ZnOEP), Ph absorption is also involved. The complex dynamics at $670-680 \mathrm{~nm}$ are attributed to the superposition of the absorption of all of the following states: singlet excited (ZnOEP) $)_{2} \mathbf{P h}$ (Dimer*) and extra-ligand $\mathbf{H}_{2} \mathbf{P} *$ states as well as CT state $\left[\operatorname{Dimer}^{+} \ldots \mathbf{H}_{2} \mathbf{P}^{-}\right]$. Thus, keeping in mind these conclusions, the following rate constants (derived directly from the experimental measurements) where used for simulation procedure: $k_{1}=8.33 \cdot 10^{8} \mathrm{~s}^{-1}$ (from the unquenched $\mathrm{Zn}$-dimer fluorescence lifetime of $1.15 \mathrm{~ns}), k_{2}=1.05 \cdot 10^{8} \mathrm{~s}^{-1}$ (from the individual $\mathbf{H}_{2} \mathbf{P}$ fluorescence lifetime of $9.5 \mathrm{~ns}$ ), $k_{3}=2.00 \cdot 10^{8} \mathrm{~s}^{-1}$ (from the signal decrease found at long delay of $4.5 \mathrm{~ns}$ which yields an estimated decay time
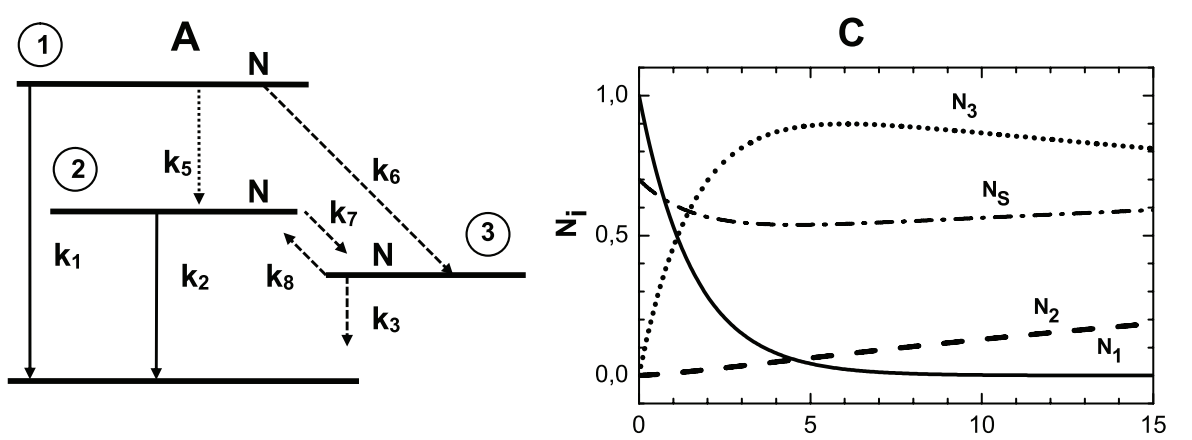

$$
\begin{gathered}
\text { B } \\
\frac{\mathrm{dN}_{1}}{\mathrm{dt}}=-\left(\mathrm{k}_{1}+\mathrm{k}_{5}+\mathrm{k}_{6}\right) \times \mathrm{N}_{1} \\
\frac{\mathrm{dN}_{2}}{\mathrm{dt}}=\mathrm{k}_{5} \times \mathrm{N}_{1}-\left(\mathrm{k}_{2}+\mathrm{k}_{7}\right) \times \mathrm{N}_{2}+\mathrm{k}_{8} \times \mathrm{N}_{3} \\
\frac{\mathrm{dN}}{\mathrm{dt}}=\mathrm{k}_{6} \mathrm{~N}_{1}+\mathrm{k}_{7} \times \mathrm{N}_{2}-\left(\mathrm{k}_{3}+\mathrm{k}_{8}\right) \times \mathrm{N}_{3}
\end{gathered}
$$

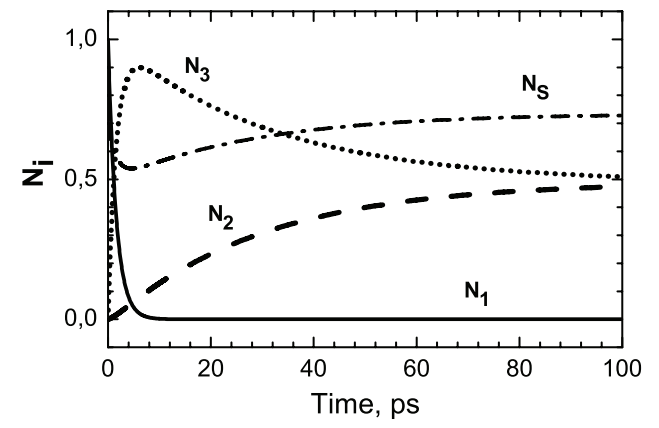

Figure 5. Schematic energy level diagram for the triad (ZnOEP $)_{2} \mathbf{P h} \otimes \mathbf{H}_{2} \mathbf{P}\left(m^{\wedge} \mathbf{P y r}\right)_{2}-(\text { iso-PrPh })_{2}$ and rate constants of relaxation processes (A); system of balance equations (B) used in calculations as well as simulated temporal dynamics population changes $(\mathbf{C})$ for locally excited singlet states of the dimer $\mathrm{N}_{1}(\mathrm{t})$, extra-ligand $\mathrm{N}_{2}(\mathrm{t})$ and singlet charge transfer $(\mathrm{CT})$ of ion-radical pair $\mathrm{N}_{3}(\mathrm{t})$ : $\mathrm{N}_{1}(\mathrm{t})(--), \mathrm{N}_{2}(\mathrm{t})(----)$ and $\mathrm{N}_{3}(\mathrm{t})(\cdots \cdot)$, and $\mathrm{N}_{\mathrm{S}}=0.8 \cdot \mathrm{N}_{1}(\mathrm{t})+0.5 \cdot \mathrm{N}_{2}(\mathrm{t})+1.0 \cdot \mathrm{N}_{3}(\mathrm{t})(-\cdot-\cdot)$. A: 1 and 2 are low-lying locally excited singlet states of the dimer (ZnOEP) ${ }_{2} \mathbf{P h}$ and the extra-ligand $\mathbf{H}_{2} \mathbf{P}$, correspondingly; 3 is the singlet charge transfer $(\mathrm{CT})$ state, ${ }^{1}\left(\mathrm{Dimer}^{+} \ldots \mathbf{H}_{2} \mathbf{P}^{-}\right)$. The triplet state of the dimer is not populated in triads and thus not shown. $\mathrm{N}$ denotes the corresponding population of states. Indicated rate constants of the following pathways: $k_{1}$, fluorescence and non-radiative decay of the dimer $(\mathbf{Z n O E P}) \mathbf{P h} ; k_{2}$, fluorescence and non-radiative decay of the extra-ligand $\mathbf{H}_{2} \mathbf{P}$ (intersystem crossing $\mathrm{S}_{1} \sim>\mathrm{T}_{1}$ in the extra-ligand is not shown); $k_{3}$, charge recombination from the radical ion pair state to the locally excited triplet state or to the ground state; $k_{5}$, singlet-singlet energy transfer from the dimer to the extra-ligand $(\mathbf{Z n O E P})_{2} \mathbf{P h}$ $\rightarrow \mathbf{H}_{2} \mathbf{P} ; k_{6}$, photoinduced electron transfer from the dimer to the extra-ligand leading to the singlet radical ion pair state formation; $k_{7}$, photoinduced hole transfer from the extra-ligand to the dimer leading to the singlet radical ion pair state formation; $k_{8}$, thermally activated charge recombination from the singlet radical ion pair state to the extra-ligand locally excited singlet state. 
of $5 \mathrm{~ns}), k_{5}=5.0 \cdot 10^{11} \mathrm{~s}^{-1}, k_{6}=1.25 \cdot 10^{11} \mathrm{~s}^{-1}\left(\left(k_{5}+k_{6}\right)^{-1}=1.6 \mathrm{ps}\right.$ from the kinetics at $510 \mathrm{~nm}$, the ratio between $k_{5}$ and $k_{6}$ chosen arbitrarily), $k_{7}=1.67 \cdot 10^{10} \mathrm{~s}^{-1}$ (from the ,slow“ $60 \mathrm{ps}$ rise of the $680 \mathrm{~nm}$ transient) and $k_{8}$ was calculated as $k_{7} \cdot \exp (-\Delta E / k \mathrm{~T})$ where $\Delta E$ is the energy difference between the excited state of $\mathbf{H}_{\mathbf{2}} \mathbf{P}$ and the charge separated state $\left[\mathrm{Dimer}^{+} \ldots \mathbf{H}_{\mathbf{2}} \mathbf{P}^{-}\right]$

As a result, based on the argued rate constants the simulation of the temporal dynamics of population changes for states $\mathbf{1}, \mathbf{2}$, and $\mathbf{3}$ were carried out and presented in Figure 5C. As it was impossible to access all of the rates involved individually it cannot be excluded that other combinations of rates (especially a different ratio $k_{5} / k_{6}$ ) would lead to a similar result. Nevertheless, these calculations do explain the behavior of the $\mathbf{H}_{2} \mathbf{P}$ fluorescence quantum yield and lifetime as well. The most interesting finding of this computational analysis (based on scheme $\mathbf{A}$ and balance equations $\mathbf{B}$, Figure 5 ) is that changing the energy difference $(\Delta \mathrm{E})$ between the excited state of $\mathbf{H}_{2} \mathbf{P}$ and the charge separated state $\left[\right.$ Dimer $\left.^{+} \ldots \mathbf{H}_{2} \mathbf{P}^{-}\right]$from $0 \mathrm{eV}$ to $0.05 \mathrm{eV}$ leads to a change in the population lifetime (i.e. fluorescence lifetime) of the $\mathbf{H}_{2} \mathbf{P}$ locally excited $\mathrm{S}_{1}$ state from $6.6 \mathrm{~ns}$ to 5.3 ns while the integrated population number (which is proportional to the quantum yield) changes from 3.3 to 0.7 arb. units. These analytical results reproduce quite well the experimental observation of little changes in the extra-ligand $\mathbf{H}_{2} \mathbf{P}$ fluorescence lifetime compared to the pronounced changes of fluorescence intensity upon self-assembly with the dimer in the triad $(\mathrm{ZnOEP})_{2} \mathbf{P h} \otimes_{2} \mathbf{P}\left(\boldsymbol{m}^{\wedge} \mathbf{P y r}\right)_{2}$-(iso-PrPh $)_{2}$.

\section{Excited States Relaxation Dynamics in Self-Assembled Triads (Theoretical Considerations)}

Despite evident theoretical and experimental progress, ${ }^{[35]}$ the calculation of the exited states dynamics of electrons or excitons in organic supramolecular aggregates is still commonly regarded as an open problem. The most successful theoretical approaches to this problem are based on a density matrix formalism and give a good agreement with experiments. ${ }^{[36]}$ However, the suitability of some simplifications used in the theoretical models is still under debate since the real systems are rather complex. ${ }^{[37]}$ In view of all this it seems to be important to analyze the electron and energy transfer and the fluorescence quenching in the self-assembled triads by numeric calculations and check whether the wellknown transfer theories can explain these complicated phenomena and give a good agreement with experimental findings in wide parameter ranges.

Because the experimentally observed kinetics discussed above do not present any trace of dynamical effects associated with the vibrational substructures it is justified to assumed that the vibrational relaxation is much faster than the electron transfer. From a theoretical point of view coherent or incoherent types of electron or exciton transport in the systems under consideration depend on the coupling to the relevant vibrational modes. In our calculations, the generalized Haken-Strobl-Reineker (HSR) method $^{[38]}$ was applied to porphyrin triads. The HSR-model is a stochastic model which allows not only both coherent or incoherent cases to be treated but also the whole range in-between. The coherent energy transport was described by the transition matrix elements between interaction subunits in the porphyrin triad. The influence of the quantum bath on a single excitation was taken into account by letting the energy of the localized excitation fluctuate and represented by a stochastic potential which is Gaussian, Markovian, and $\delta$-correlated in time. Three quantum states (shown in Scheme 1) were taken into account for the triad $(\mathrm{ZnOEP})_{2} \mathbf{P h} \otimes_{2} \mathbf{P}\left(m^{\wedge} \mathbf{P y r}\right)_{2}$-(iso-PrPh $)_{2}$.

For the triads containing the dimer (ZnOEP), Ph and the extra-ligand $\mathbf{H}_{\mathbf{2}} \mathbf{P}$, the dynamics of the excited states $|1\rangle=\left|\operatorname{Dimer}^{*}-\mathbf{H}_{2} \mathbf{P}\right\rangle,|2\rangle=\left|\operatorname{Dimer}^{+}-\mathbf{H}_{2} \mathbf{P}^{-}\right\rangle$, and $|3\rangle=\mid$ Dimer $\left.\mathbf{H}_{2} \mathbf{P}^{*}\right\rangle$ is described by the equation of motion for the relevant reduced density matrix in the HSR-mode ${ }^{[38,39]}$ with neglecting of the vibrational substructure of the electronic states ${ }^{[40]}$ as follows:

$$
\begin{aligned}
& \frac{\partial}{\partial t} \sigma_{\kappa \lambda}=-\frac{i}{\hbar}\left(\left[H_{S}, \sigma\right]\right)_{\kappa \lambda}+2 \delta_{\kappa \lambda}\left\{\Gamma_{\mu \kappa}\left[n\left(\omega_{\mu \kappa}\right)+1\right]+\Gamma_{\kappa \mu} n\left(\omega_{\kappa \mu}\right)\right\} \sigma_{\mu \mu} \\
& -\Sigma_{\mu}\left\{\Gamma_{\mu \kappa}\left[n\left(\omega_{\mu \kappa}\right)+1\right]+\Gamma_{\kappa \mu} n\left(\omega_{k \mu}\right)+\Gamma_{\mu \lambda}\left[n\left(\omega_{\mu \lambda}\right)+1\right]+\Gamma_{\lambda \mu} n\left(\omega_{\lambda \mu}\right)\right\} \sigma_{\kappa \lambda} \\
& +\left\{\Gamma_{\lambda \kappa}\left[2 n\left(\omega_{\lambda \kappa}\right)+1\right]+\Gamma_{\kappa \lambda}\left[2 n\left(\omega_{\kappa \lambda}\right)+1\right]\right\} \sigma_{\lambda \kappa} .
\end{aligned}
$$

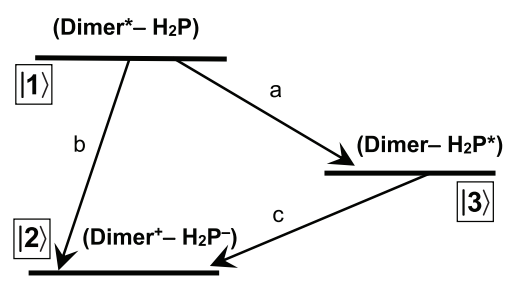

Scheme 1.

Here, the triad Hamiltonian $H_{\mathrm{S}}$ includes the energies $E_{\lambda}$ of the corresponding states and couplings between them, $n(\omega)=\left[\exp \left(\hbar \omega / k_{\mathrm{B}} T\right)-1\right]^{-1}$ denotes the Bose-Einstein distribution, $\Gamma_{k \lambda}$ is the damping constant, and $k, \lambda, \mu=1,2,3$. For the sake of convenience of the numerical calculations we replace $\Gamma_{\mu v}$ and the population of the corresponding bath mode $n\left(\omega_{\mu \nu}\right)$ with the dissipative transitions $d_{\mu \nu}=\Gamma_{\mu v}\left|n\left(\omega_{\mu \nu}\right)\right|$ and the corresponding dephasings $\gamma_{\mu \nu}=\sum_{\mathrm{k}}\left(d_{\mu \nu}+d_{\mu \nu}\right) / 2$. In such a model one describes the porphyrin triad with the relevant potential energy surfaces in the space of a single reaction coordinate, which reflect the extent of the solvent polarization induced by the field of the triad.

In order to allow the analysis of absorption and emission spectra one should add to the model a ground state potential $|0\rangle$. For the neutral excited states $|1\rangle$ and $|3\rangle$ the difference in absorption and emission spectra of the ground-excited transition determines the shift $q_{\mu 0}$ of the equilibrium point of the excited state $|\mu\rangle=|1\rangle,|3\rangle$ in respect to the equilibrium point of the ground state $|0\rangle$. The shift of the equilibrium point of the charge separated state $|2\rangle q_{20}$ can be calculated using the reorganization energy of the solvent:

$$
\lambda_{20}=m \omega_{\text {vib }}^{2} q_{20}^{2} \frac{\mathrm{e}^{2}}{4 \pi \varepsilon_{0}}\left(\frac{1}{2 r_{\mathrm{D}}}+\frac{1}{2 r_{\mathrm{A}}}-\frac{1}{r_{\mathrm{DA}}}\right)\left(\frac{1}{\varepsilon_{\infty}}-\frac{1}{\varepsilon_{0}}\right) .
$$

Here $\omega_{\text {vib }}$ is the leading (mean) environment oscillator frequency, $m$ its mass, $\varepsilon$ and $\varepsilon_{\infty}$ stand for static and optical 
dielectric constant of the solvent and $\varepsilon_{0}$ is the dielectric constant of vacuum, $r_{\mathrm{D}}=r_{\mathrm{A}}=5.5 \AA$ are the donor and acceptor radius, respectively, $r_{\mathrm{DA}}=8.8 \AA$ (for the triad $\mathbf{Z n O E P})_{2} \mathbf{P h} \otimes_{2} \mathbf{P}\left(\boldsymbol{m}^{\wedge} \mathbf{P y r}\right)_{2}$-(iso-PrPh $)_{2}$, Figure $\left.1 \mathrm{~A}\right)$. We assume that the sign of the shift for the state $|3\rangle$ should be negative with respect to the signs of the shifts of $|1\rangle$ and $|2\rangle$. The range of reasonable values of relaxation constants $\Gamma_{\mu v}$ (coupling) was estimated using the width of the relevant bands in the absorption spectra of the porphyrin triad (presented in Table 3).

In order to describe the relaxation processes in the triads physically reasonable values of the model parameters, such as the energies of locally excited $\mathrm{S}_{1}$ states and CT states as well as coherent and dissipative couplings have to be appropriately chosen. For the triads under consideration, the energies $E_{1}=2.1 \mathrm{eV}$ (locally excited $\mathrm{S}_{1}$ state of the dimer (ZnOEP) $\mathbf{2} \mathbf{P h}), E_{2}=1.90 \mathrm{eV}$ (CT state in toluene at $293 \mathrm{~K}$, Table 2) and $E_{3}=1.91 \mathrm{eV}\left(\mathrm{S}_{1}\right.$ state of the extra-ligand $\left.\mathbf{H}_{2} \mathbf{P}\right)$ are taken from our results presented above. The energy of CT state $|2\rangle$ depending on the solvent polarity was calculated using Weller's formula: ${ }^{[41]}$

$$
E_{2}(\varepsilon)=E_{2}\left(\varepsilon_{t}\right)+\left(\frac{1}{\varepsilon}-\frac{1}{\varepsilon_{t}}\right) \frac{e^{2}}{4 \pi \varepsilon_{0}}\left(\frac{1}{2 r_{D}}+\frac{1}{2 r_{A}}-\frac{1}{r_{D A}}\right)
$$

In the case the solvent mixture consisting of toluene and a small amount of acetone the effective dielectric constant of the mixture may be found assuming that the Onsager function of the mixture is a sum of the Onsager functions of the individual components. ${ }^{[42]}$ Using known $\mathrm{D}$ and A radii $r_{\mathrm{D}}, r_{\mathrm{A}}, r_{\mathrm{DA}}$ distances in the triads and solvent properties (presented and discussed above) the values of the reorganization energy were calculated according to ${ }^{[24,25]}$

$$
\lambda_{\text {solv }}=\frac{e^{2}}{4 \pi \varepsilon_{0}}\left[\frac{1}{2 r_{D}}+\frac{1}{2 r_{A}}-\frac{1}{r_{D A}}\right] \cdot\left[\frac{1}{\varepsilon_{o p}}-\frac{1}{\varepsilon}\right]
$$

Table 3 contains the reasonable values of the couplings and relaxation constants (used in calculations) estimated from experimentally obtained data for porphyrins and triads.

As it follows from the experimental results for the triads at ambient temperature, the competition between EET and PET manifests itself in a rather complex non-radiative dynamics of the excited states. Mathematically it is easy to calculate the system state at infinite time $t=\infty$. We found that for the triad $(\mathbf{Z n O E P})_{2} \mathbf{P h} \otimes \mathbf{H}_{2} \mathbf{P}\left(m^{\wedge} \mathbf{P y r}\right)_{2}$-(iso-PrPh $)_{2}$ in toluene at $293 \mathrm{~K}$ the electron transfer time $\left(\mathrm{t}_{\mathrm{PET}} \approx 1.7 \mathrm{ps}\right)$ is much shorter than the fluorescence decay time of extraligand $\mathbf{H}_{2} \mathbf{P}\left(\tau_{\mathrm{S}}{ }^{\mathrm{L}}=7.7 \mathrm{~ns}\right.$, see Table 2$)$. Thus, we may approximate $\mathrm{t}=\infty$ with some time moment $t$ when the electron transfer finished and the fluorescence did not occurr yet. In this time $\mathrm{t}_{\mathrm{PET}}<t<\tau_{\mathrm{S}}$ the system reaches the quasi-thermal equilibrium between the excited state $|3\rangle$ and the close lying CT state $|2\rangle$.

For each parameter set the relevant reduced density matrix $\sigma_{\mathrm{k} \lambda}(t)$ was numerically calculated. At $\mathrm{t}=\infty$ the diagonal elements of density matrix arrive to the quasi-equilibrium values. Really, these values correspond to the stationary fluorescence intensity of the triad subunits. Here we are interested in the equilibrium population of the state $|3\rangle$ calculated numerically with the generalized HSR method. We denote the population of this state with $\mathrm{P}_{\mathrm{DA}^{*}}=\rho_{33}$. Taking into account parameters collected in Table 3 it was found that $\mathrm{P}_{\mathrm{DA}^{*}}(\infty)$ decreases in two cases: (i) lowering of the CT state energy $E_{2}$ (induced by increasing the solvent polarity) and (ii) lowering the temperature. As one can see from Figure 6 , the calculated dependences $\mathrm{P}_{\mathrm{DA}^{*}}(\infty)$ of the extra-ligand $\mathbf{H}_{2} \mathbf{P}$ population in the $S_{1}$ state on temperature and solvent polarity are in a reasonable agreement with the observed fluorescence quenching. Thus, one may conclude that the observed fluorescence quenching of the extra-ligand $\mathbf{H}_{2} \mathbf{P}$ in the triad is realized via hole transfer $|3\rangle \rightarrow|2\rangle$ from the extra-ligand to the dimer (ZnOEP) $\mathbf{P h}$ weakened by thermal exchange of the close lying charge transfer and extra-ligand locally excited $\mathrm{S}_{1}$ states. The variation of the solvent polarity (acetone addition) and temperature changes the $\mathbf{H}_{\mathbf{2}} \mathbf{P}$ fluorescence intensity (the population $\rho_{33}$ ) as well as the character of the excited states dynamics.

Finally, the theoretical analysis in the frame of the generalized Haken-Strobl-Reineker approach ${ }^{[38]}$ shows that the time dependence of the population $\rho_{33}$ as well as its temperature dependence at low acetone concentration qualitatively differ from the behavior at high acetone concentration (what is not evident from experimental findings). It means that under various experimental conditions different reaction mechanisms may be realized. Theory predicts that at low acetone concentrations (0-7 vol.\%) the quasi-thermal equilibrium population $\mathrm{P}_{\mathrm{DA}^{*}}(\infty)$ is reached in one-step (due to the energy transfer EET process presumably) and a reaction rate constant can be found with an one-exponential fit. In the case of high acetone concentration (10-20 vol.\%) the energy detuning between states $|2\rangle$ and $|3\rangle$ becomes larger.

\begin{tabular}{|c|c|c|c|}
\hline Coupling & Value, meV & Physical Process & Comment \\
\hline$v_{12}$ & 20 & Electron transfer $\mathrm{D}^{*} \mathrm{~A} \rightarrow \mathrm{D}^{+} \mathrm{A}^{-}$ & Induced by the wave function overlap \\
\hline$v_{32}$ & 3 & Hole transfer $\mathrm{D}^{*} \mathrm{~A} \rightarrow \mathrm{D}^{+} \mathrm{A}^{-}$ & $\begin{array}{l}\text { Weakened by the screening field of the electron from the LUMO } \\
\text { of the acceptor }\end{array}$ \\
\hline$v_{13}$ & $<12$ & Energy transfer $\mathrm{D}^{*} \mathrm{~A} \rightarrow \mathrm{DA}^{*}$ & Induced by the dipole-dipole interaction $v_{13} \sim \mu_{\mathrm{D}} \times \mu_{\mathrm{A}} / r_{\mathrm{DA}}{ }^{3}$ \\
\hline$\Gamma_{12}$ & 0.41 & Loss of coherence for $\mathrm{D}^{*} \mathrm{~A} \rightarrow \mathrm{D}^{+} \mathrm{A}^{-}$ & Interaction of the transition dipole moment with environmental dipoles \\
\hline$\Gamma_{32}$ & 2.50 & Loss of coherence for $\mathrm{D}^{*} \mathrm{~A} \rightarrow \mathrm{D}^{+} \mathrm{A}^{-}$ & Induced by the interaction with the environment \\
\hline$\Gamma_{13}$ & 0.37 & Loss of coherence for $\mathrm{D}^{*} \mathrm{~A} \rightarrow \mathrm{DA}^{*}$ & Estimated by taking into account another dissipation $\gamma_{i j}=\sum_{\mathrm{k}}\left(\mathrm{d}_{\mathrm{ki}}+\mathrm{d}_{\mathrm{ik}}\right)$ \\
\hline
\end{tabular}

Table 3. Coherent and dissipative couplings between electronic states for the triad $(\mathbf{Z n O E P})_{2} \mathbf{P h} \otimes \mathbf{H}_{2} \mathbf{P}\left(m^{\wedge} \mathbf{P y r}\right)_{2}-(\text { iso-PrPh })_{2}$. 

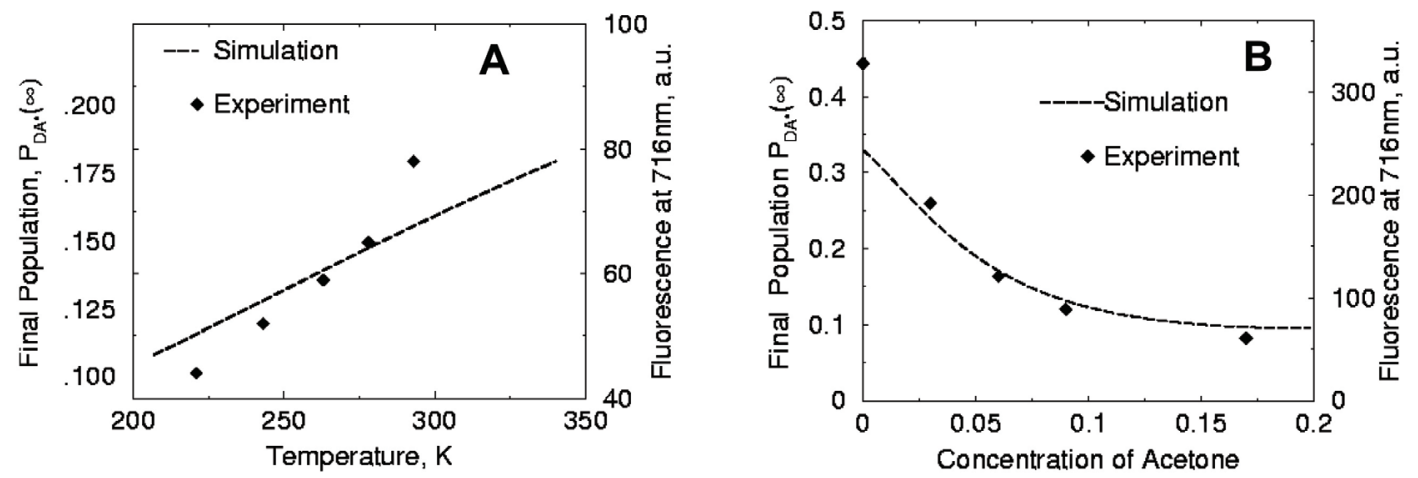

Figure 6. Comparison of experimental and theoretical temperature (A) and solvent polarity (B) dependences of the fluorescence band intensity at $716-720 \mathrm{~nm}$ (belonging to the extra-ligand $\mathbf{H}_{2} \mathbf{P}$ in the triad $(\mathbf{Z n O E P})_{2} \mathbf{P h} \otimes \mathbf{H}_{2} \mathbf{P}\left(\boldsymbol{m}^{\wedge} \mathbf{P y r}\right)_{2}-(\boldsymbol{i s o}-\mathbf{P r P h})_{2}$. A: Temperature dependence in toluene plus 7 vol.\% of acetone; in a temperature range, where the triad formation is complete, experimental points (integrated intensities of the extra-ligand fluorescence band at 716-720 nm) were reasonably fitted by a two level Boltzman distribution

function $f(\mathrm{~T}) \propto$ const $+\frac{1}{1+\exp \left(-\frac{\Delta E}{k \mathrm{~T}}\right)}$.

At $\mathrm{T}>280 \mathrm{~K}$ the deviations of experimental points with respect to the theoretical dependence (dashed line) are caused by a partial decomposition of the triads upon solution heating. B: Experimental points are obtained from the results shown in Figure 3A. The simulations of the equilibrium population $\mathrm{P}_{\mathrm{DA}}$ were carried out using the generalized HSR theory for the description of the photoinduced processes in the triads.

Correspondingly, in addition to the EET process, the hole transfer $|3\rangle \rightarrow \| 2\rangle$ takes place, thus the equilibrium population $P_{D^{*}}(\infty)$ is reached in two steps. The reaction occurs with the help of a sequential transfer, which is described by two rates (increase and decrease), and the one-exponential fit for a reaction rate constant cannot be used in this case. At last, it is interesting to note, that at high acetone concentrations (10-20 vol.\%) the energy gap $\Delta E=E_{3}-E_{2}$ becomes larger (due to stabilization of the CT state), and two regimes $k_{\mathrm{B}} \mathrm{T}>$ $\Delta E$ and $k_{\mathrm{B}} \mathrm{T}<\Delta E$ may be realized upon temperature changing. The first case corresponds to the one-step reaction, while the second case reflects the two-step reaction. It means that for high acetone admixture in toluene the increase of temperature induces the crossover from the second (coherent) to the first (incoherent) type of quantum particle transport. The simulations demonstrate that the crossover from one to second type of the transport in the triad $(\mathrm{ZnOEP})_{2} \mathbf{P h} \otimes \mathrm{H}_{2} \mathbf{P}\left(m^{\wedge} \mathbf{P y r}\right)_{2}$-(iso-PrPh $)_{2}$ takes place at different temperatures for the various acetone admixture concentration. It means that the crossover temperature depends on the dielectric constant of a solvent.

\section{Conclusions}

From the basic point of view, upon studying the properties and possible functionalities of artificial multicomponent organic complexes the basic task seems to be the analysis of spectral-structural correlations as well the mechanisms of interchromophoric interactions depending on the morphology of the given nanostructures. Keeping this idea in mind, here we present and discuss results of quantitative experimental studies of basic non-radiative competitive relaxation processes (excitation energy transfer and photoinduced charge separation) for self-assembled triads based on $\mathrm{Zn}$ - octaethylporphyrin chemical dimers (the energy/electron donor) and dipyridyl substituted porphyrin extra-ligands (acceptors). Using steady-state spectroscopy, time correlated single photon counting technique, and femtosecond pumpprobe spectroscopy applied for the triads with well-established morphology and composition, pathways, mechanisms, and efficiencies of the non-radiative relaxation processes were studied upon variation of temperature and solvent polarity.

In addition, we simulated the physical processes in self-assembled porphyrin triads in non-polar toluene and in a mixture of solvents with different dielectric constants. Using the generalized HSR-model we calculated the intensity of the triad fluorescence (originated from the extra-ligand $\mathbf{H}_{2} \mathbf{P}$ ) and its dependence on temperature and solvent polarity. Theoretical dependences are in a reasonable qualitative and quantitative agreement with the experimental findings obtained. On the base of the experimental and theoretical investigations it was concluded that both electronic excitation energy transfer (ZnOEP) 2 Ph $\rightarrow$ extraligand and charge separation processes cause the quenching of the dimer locally excited $S_{1}$ state. The quenching of the extra-ligand $\mathrm{S}_{1}$ state originates from the hole transfer to the dimer from the extra-ligand weakened by the thermal exchange of the close lying charge transfer and extra-ligand locally excited $\mathrm{S}_{1}$ state.

The presented research enriches our quantitative understanding on the self-assembly of porphyrin molecules in the triads with well-defined geometry and the correlation with the photophysical processes therein, possibly leading to the realization of new types of solar power conversion devices. Moreover, the detailed experimental and theoretical analysis of the structure-properties correlations in the systems under study permitted us to explain some unusual and rare events which may be realized in multiporphyrin complexes and shortly presented below. 
It should be noted that in toluene at $293 \mathrm{~K}$, the extraligand $\mathbf{H}_{2} \mathbf{P}$ decay shortening $\left(\tau_{\mathrm{S}}^{\mathrm{L}}\right.$ values, Table 2$)$ has the same order of magnitude for all triads with different geometries (structures $\mathbf{A}, \mathbf{B}$ and $\mathbf{C}$, Figure 1). It means that deviations of intercenter distances $r_{\mathrm{DA}}$ for these triads (having different orientations of porphyrin free base with respect to the dimer plane) do not lead to principal changes of the electron transfer rate constants. This fact may be explained by the close proximity of extra-ligand macrocycles to the $\pi$-conjugated electronic system of the dimer (ZnOEP), Ph. As a result, the electronic coupling determined by the overlap of $\mathrm{D}$ and A periphery orbitals is strong enough and does not change essentially upon the geometrical reorganization of the same electron acceptor in the triad. The second reason of the same quenching effect observed for triads with different geometries may be connected with the possible role of pyridyl rings as spacers between interacting D and A subunits. According to arguments discussed for both the HOMO and the LUMO, ${ }^{[30,32,43]}$ the orbital density is greater at the ortho- and para-positions compared to that at the meta-position of the phenyl spacer. Therefore, it seems reasonable to suggest that this tendency is operative in the triads. Correspondingly, the electronic coupling of the dimer and the extra-ligand, as mediated by the superexchange interactions, ${ }^{[43]}$ will also be strong in the paracase, $\mathbf{H}_{2} \mathbf{P}\left(\boldsymbol{p}^{\wedge} \mathbf{P y r}\right)_{2}$, in spite of greater intercenter distance $r_{\mathrm{DA}}$ with respect to the metha-case $\mathbf{H}_{2} \mathbf{P}\left(\boldsymbol{m}^{\wedge} \mathbf{P y r}\right)_{2}$.

At last, a final comment should be added to the results and conclusions of this study. We demonstrated ${ }^{[44]}$ that in non-degassed toluene solutions at $293 \mathrm{~K}$ upon laser excitation, the porphyrin triads are effective sensitizers of singlet oxygen (like individual porphyrin free bases) with manifestation of extra-ligation and screening effects. Interestingly, the transient absorption spectrum of the triad $(\mathbf{Z n O E P})_{2} \mathbf{P h} \otimes \mathbf{H}_{2} \mathbf{P}-\left(\boldsymbol{m}^{\wedge} \mathbf{P y r}\right)_{2}$-(iso-PrPh $)_{2}$ at $4.5 \mathrm{~ns}$ delay time corresponds better to known transient T-T spectra for porphyrin free bases measured at ms time scales and differs principally from that detected at $\mathrm{ps} /$ fs delay times (Figure $4 \mathrm{~B}$ in this paper). On the base of all these facts it is reasonable to assume that the population of the locally excited and low-lying $\mathrm{T}_{1}$-state of porphyrin extra-ligands in triads takes place from the upper-lying radical ion pair CT state. In this respect, self-assembled porphyrin triads may be considered as very rare electron-acceptor synthetic model systems in which a single electron transfer step produces radical ion pairs at a short $(\sim 11 \AA)$ distance with a large exchange integral $J$ that leads to the efficient formation of locally excited $\mathrm{T}_{1}$ states. ${ }^{[45]}$

Acknowledgements. Financial support from the program BSPSR “Convergence-2020 3.03”, BRFBR Grant No Ф18P-314 (Belarus-Russia), Volkswagen project No I/79 435 (Germany) and Grant of President of Republic of Belarus (2020) is gratefully acknowledged.

\section{References}

1. Cook T.R., Dogutan D.K., Reece S.Y., Surendranath Y., Teets T.S., Nocera D.G. Chem. Rev. 2010, 110, 6474-6502.

2. Otsuki J. J. Mater. Chem. A 2018, 6, 6710-6753.
3. Croce R., van Amerongen H. Nat. Chem. Biol. 2014, 10, 492-501.

4. Unterkofler S., Pflock T., Southall J., Cogdell R.J., Koehler J. ChemPhysChem 2011, 12, 711-716.

5. Snellenburg J.J., Johnson M.P., Ruban A.V., van Grondelle R., Stokkum I.H.M. BBA Bioenergetics 2017, 1858, 854-864.

6. Moretti L., Kudisch B., Terazono Y., Moore A.L., Moore T.A., Gust D., Cerullo G., Scholes G.D., Maiuri M. J. Phys. Chem. Lett. 2020, DOI: 10.1021/acs.jpclett.0c00856.

7. Kundu S., Patra A. Chem. Rev. 2017, 117, 712-757.

8. Multiporphyrin Arrays: Fundamentals and Applications (Kim D., Ed.) Singapore: Pan Stanford Publishing Pte. Ltd., 2012. $775 \mathrm{p}$.

9. Zenkevich E.I., von Borczyskowski C. Formation Principles and Excited States Relaxation in Self-Assembled Complexes: Multiporphyrin Arrays and "Semiconductor CdSe/ZnS Quantum Dot-Porphyrin" Nanocomposites. In: Handbook of Porphyrin Science with Application to Chemistry, Physics, Materials Science, Engineering, Biology and Medicine. Vol. 22 - Biophysical and Physicochemical Studies of Tetrapyrroles (Kadish K., Smith K.M., Guilard R., Eds.) Singapore: World Scientific Publishing Co. Pte. Ltd., 2012. pp. 67-168.

10. Fukuzumi S., Lee Y.-M., Nam W. ChemPhotoChem 2018, 2, 121-135.

11. Hood D., Sahin T., Parkes-Loach P.S., Jiao J., Harris Michelle A., Dilbeck P., Niedzwiedzki D.M., Kirmaier C., Loach P.A., Bocian D.F., Lindsey J.S., Holten D. ChemPhotoChem 2018, 2, 300-313.

12. Zeng Y., Chen J., Yu T., Yang G., Li Y. ACS Energy Lett. 2017, 2, 357-363.

13. Wibmer L., Lourenco L.M.O., Roth A., Katsukis G., Neves M.G.P., Cavaleiro J.A.S., Tomé J.P.C., Torres T., Guldi D.M. Nanoscale 2015, 7, 5674-5682.

14. Zenkevich E.I., Larkina E.A., Konovalova N.V., Stupak A.P. Macroheterocycles 2019, 12, 47-57.

15. Zenkevich E.I. Russ. J. Gen. Chem. 2019, 89(12), 1-32.

16. Pal K. Hybrid Nanocomposites: Fundamentals, Synthesis, and Applications. 1st Edition, Jenny Stanford Publishing, 2019.

17. Cassano D., Voliani V. Behaviors and Persistence of Nanomaterials in Biomedical Applications. Scrivener Publishing LLC. John Wiley \& Sons, Inc., 2018.

18. Kiat J.H. Nanomaterials in Energy Devices. CRC Press, 2017. $248 \mathrm{p}$.

19. Lehn J.-M. Supramolecular Chemistry: Concept and Perspectives. VCH, Weinheim, 1995.

20. Hill J.P., D’Souza F., Ariga K. In: Supramolecular Chemistry: From Molecules to Nanomaterials (Gale P., Steed J., Eds.) Wiley, 2012. p. 1713-1730.

21. Foerster T. Modern Quantum Chemistry. New York: Academic Press, 1965.

22. Agranovich V.M., Galanin M.D. Electronic Excitation Energy Transfer in Condensed Matter. Moscow: Nauka, 1977 (in Russ.) [Агранович В.М., Галанин М.Д. Перенос энергии электронного возбуждения в конденсированных средах. М.: Наука, 1978. 383 с.].

23. Govorov A., Hernández P.L., Hilmi M., Demir V. Understanding and Modeling Förster-type Resonance Energy Transfer (FRET): Introduction to FRET. Springer Briefs in Applied Sciences and Technology. Singapore: Springer, 2016.

24. Marcus R.A. Rev. Modern Phys. 1993, 65, 599-610.

25. Wasielewski M.R. Chem. Rev. 1992, 92, 435-461.

26. Bixon M., Jortner J., Michel-Beyerle M.E. Chem. Phys. 1995, 197, 389-404.

27. Zenkevich E.I., von Borczyskowski C. Multiporphyrin SelfAssembled Arrays in Solutions and Films: Thermodynamics, Spectroscopy and Photochemistry. In: Handbook of Poly- 
electrolytes and Their Applications (Tripathy S.K., Kumar J., Nalwa H.S., Eds.) USA: American Scientific Publishers, 2002, Vol. 2, Ch. 11. pp. 301-348.

28. Zenkevich E.I., von Borczyskowski C. Photoinduced Relaxation Processes in Self-Assembled Nanostructures: Multiporphyrin Complexes and Composites "CdSe/ZnS Quantum Dot-Porphyrin”. In: Multiporphyrin Arrays: Fundamentals and Applications (Kim D., Ed.) Singapore: Pan Stanford Publishing Pte. Ltd., 2012, Ch. 5. pp. 217-288.

29. Chernook A.V., Shulga A.M., Zenkevich E.I., Rempel U., von Borczyskowski C. J. Phys. Chem. 1996, 100(5), 1918-1926.

30. Zenkevich E.I., von Borczyskowski C., Shulga A.M., Bachilo S.M., Rempel U., Willert A. Chem. Phys. 2002, 275(1-3), 185-209.

31. Zenkevich E.I., Tikhomirov S.A. Femtosecond Transient Spectroscopy of Solutions. In: Theoretical and Experimental Methods of Solution Chemistry (Tsivadze A.Yu., Ed.) Moscow, 2011, Chart 4. pp. 184-248 (in Russ.) [Зенькевич Э.И., Тихомиров С.А. Фемтосекундная транзиентная спектроскопия растворов. В кн. Теоретические $u$ экспериментальные методы химии растворов (Цивадзе А.Ю., ред.). М.: Изд-во Проспект, 2011. Гл. 4, с. 184-248].

32. Zenkevich E.I., Shulga A.M., Chernook A.V., Sagun E.I., Gurinovich G.P. Proc. Indian Acad. Sci., Chem. Sci. 1995, 107, 795-802.
33. Kavarnos G.J., Turro N.J. Chem. Rev. 1986, 86, 401-449.

34. Murrov S.L., Carmichael I., Hug G.L. Handbook of Photochemistry. New-York-Basel-Hong Kong: Marcel Deccer Inc., 1993. pp. 269-278.

35. Brixner T., Hildner R., Köhler J., Lambert C., Würthner F. Adv. Energy Mater. 2017, 7(16), 1700236.

36. Renger T., May V. J. Phys. Chem. B 1997, 101, 7232-7240.

37. Meier T., Chernyak V., Mukamel S. J. Chem. Phys. 1997, 107, 8759-8774.

38. Reineker V.M. In: Exciton Dynamics in Molecular Crystals and Aggregates (Höhler G., Ed.) Springer Tracts in Modern Physics, Berlin: Springer, 1982, 94. p. 111.

39. Herman P., Barvik I. Phys. Rev. B 1993, 48, 3130-3013.

40. Schreiber M., Kilin D., Kleinekathoefer U. J. Lumin. 1999, 83-84, 235-240.

41. Weller A. Z. Phys. Chem. Neue Folge 1982, 13, 93-97.

42. Supan P. J. Chem. Soc. Farad. Trans. I 1987, 83, 495-499.

43. Gust D., Moore T.A., Moore A.L., Devados C., Liddell P.A., Hermant R., Nieman R.A., Demanche L.G., DeGraziano J.M., Gouni I. J. Am. Chem. Soc. 1992, 3590-3602.

44. Sagun E.I., Zenkevich E.I., Knyukshto V.N., Shulga A.M., Starukhin D.A., von Borczyskowski C. Chem. Phys. 2002, 275(1-3), 211-237.

45. Wiederrecht G.P., Svec W.A., Wasielewski M.R., Galili T., Levanon H. J. Am. Chem. Soc. 1999, 121, 7726-7727.

Received 18.06.2020

Accepted 09.07.2020 